\title{
Effects of Parameters on Cashew Nutshell and Cassava Binder Briquettes Densification: Structural Equation Modelling
}

\author{
Stephen K. Kimutai
}

\section{ABSTRACT}

Densification improves the properties of loose biomass for use as fuels, and the process is a complex technological problem involving the interaction of variables that are interdependent on one another. The effects of process variables (pressure and dwell time) and a material variable (percentage binder, particle size, and mass) on the density of cashew nutshell and cassava binder briquettes were investigated using structural equation modelling (SEM) with the help of AMOS version 23 software. A furnace was used to carbonize cashew nut shells at temperatures of $250{ }^{\circ} \mathrm{C}$. The pulverized charcoal from the carbonization process was used to create briquettes with cassava paste as the binding medium. Different particle sizes of $0.5 \mathrm{~mm}, 1 \mathrm{~mm}$, and $2 \mathrm{~mm}$ were used to create briquettes. Different compaction pressures (9.81 MPa, 19.6 MPa, and 29.42 MPa) were used in the absence and presence of various binder ratios $(10 \%, 20 \%$ and $30 \%)$. SEM analysis found that factors pressure ((Path coefficient $(\beta)=493)$, binder percentage $(\beta=0$. 406), mass $(\beta=0.257)$ and dwelling time $(\beta=0$. 173) positively influence the density of cashew nutshell and cassava binder briquettes and conversely for particle size $(\beta=-0.505, C . R=-6.010)$. In addition, SEM model showed that a particle size has the strongest effects on the density of the briquettes followed by compacting pressure and thirdly binder percentage. This study provides a better understanding of some of the factors that influence making of briquettes from cashew nutshell and cassava binder.

Keywords: Briquettes, Cashew nuts, Cassava, Density, SEM.

Published Online: June 25, 2021

ISSN: $2736-5506$

DOI : $10.24018 /$ ejenergy.2021.1.2.10

Stephen K. Kimutai*

Department of Mechanical, Production \& Energy Engineering, School of Engineering, Moi University, Kenya.

(e-mail: mantuikong@gmail.com)

*Corresponding Author

\section{INTRODUCTION}

Global energy demand continues to rise, coupled with an over-reliance on fossil fuels, is hindered by negative environmental effects caused by carbon dioxide emissions during combustion, which contribute to global warming. Majority of Kenyans rely on biomass (firewood) as the most common energy resource used for cooking in both rural and peri urban areas [1]-[3], whose sustainability is faced with diminishing forest cover. As a result, alternative environmentally sustainable and open sources must be sought. Alternative fuel sources include cashew nut shells and cassava, both of which are currently considered to have low economic value.

The use of wood and agricultural residues for both domestic and industrial fuel has greatly improved thanks to the densification of residue materials. Densification provides a number of benefits, including: (i) improved handling, durability, and transportation, (ii) regulated particle size distribution for improved feedstock uniformity and density, (iii) improved compressive strength, (iv) increase in calorific value, (v) quality of fuel such combustion time, specific fuel consumption and colour flame and (vi) conformance to predetermined alteration technology and supply system requirements [4]-[9]. Briquettes made at lower pressures (10 to $60 \mathrm{MPa}$ ) are said to fall apart easily. Briquettes made at higher pressures (150 to $250 \mathrm{MPa}$ ) are, on the other hand, more consistent and lightweight. Furthermore, briquette density and durability are inversely proportional to particle size since smaller particles have more surface area during densification. Therefore, there is need to understand other factors that influence making of briquettes through densification.

Bagasse, rice husks, cashew nut shells, maize cobs, rice straws, cassava, and coconut shells, among other agricultural residues, can be used to minimize the over-reliance on wood resources as a source of fuel [7], [10]-[15]. These residues have a lot of potential in the country [16], but they haven't been used yet because of their low density, which leads to combustion and handling problems [11], [17], [18]. 
The cashew nut is a significant agricultural crop in Kenya, as well as many other parts of the world. The crop is grown along the coast in Kenya's Kwale, Mombasa, Kilifi, Lamu, Tana River, and Taita Taveta counties. Kenya produces an average of 24000 tons per year (5.9\% of global output) [19].The aim of this study was to look into making fuel briquettes from cashew nut residues using the hydraulic densification method and cassava binder. The effect of mass, dwelling time, particle size, and compacting pressure on the relaxed density of fuel briquettes made at room temperature with low compacting pressure is also investigated in this analysis.

\section{MATERIALS AND METHODS}

\section{A. Preparation of Cashew nut shells charcoal}

Sun dried cashew nut shells from Kenya's coast were sorted for any foreign material such as stones after being sun dried for 2-4 days. The shells were placed in a metal box and baked for 3 hours at $250{ }^{\circ} \mathrm{C}$ to achieve the best results [20]. Using milling machines, the burnt shells were ground down. After that, the milled charcoal was sieved to obtain samples of three different particle sizes: $0.5 \mathrm{~mm}, 1.0 \mathrm{~mm}$, and $2.0 \mathrm{~mm}$. The residual particles larger than $2.0 \mathrm{~mm}$ were then transferred to a motorized mill, where they were further pulverized into smaller particle sizes before being sieved again.

\section{B. Briquettes Making Process}

With compaction pressures of 9.81 MPa, 19.6 MPa, and $29.42 \mathrm{MPa}$, particle sizes of $0.5 \mathrm{~mm}, 1 \mathrm{~mm}$, and $2 \mathrm{~mm}$, and dwell times of $0 \mathrm{~min}, 1$ minutes, and 2 minutes, a mixture of cashew nut shell charcoal with and without binders was fed into a hydraulic press for briquette development. Briquettes were produced stored under room temperature to dry. The relaxed densities of briquettes were determined 30 days after the briquetting process as recommended by Kpalo et al [21] and Lamidi et al[22].

\section{SEM Modelling}

The AMOS 23.0 software package was employed to study SEM path coefficients. Model definition, identification, parameter estimation, model evaluation, and model adjustment were the five conceptual measures used in SEM. Model specification in SEM specified the hypothesized relationships among the variables based on the objectives, while model identification was used to determine whether the model was identified. In the just identified or over-identified model, model coefficients were discovered. The model's fitness was then assessed using model assessment, with quantitative indices for overall goodness of fit measured. Modification was done in the process to change the model to enhance model fit, i.e., post hoc model modification.

The SEM assessment was based on the fit indices for evaluating a single path coefficient (i.e., p value, standard error and critical ratio) and the overall fit model (i.e., $\chi 2$,
RMSEA, GFI) [23], [24]. Table I displays the model health and acceptance level in SEM research. The goodness-of-fit index (GFI), the modified goodness-of-fit index (AGFI), parsimony-adjusted normed fit index (PNFI), parsimonyadjusted Comparative fit index (PCFI) [20], and root mean square error (RMSE) are among the model fitness parameters [25], [26], parsimony-adjusted normed fit index (PNFI), parsimony-adjusted Comparative fit index (PCFI)[27] and root mean square error of approximation (RMSEA) [28]. With CR values greater than 1.96 or less than -1.96 and a low standard error with significance at the $p \leq 0.05$ value, the $C R$ is also a widely recommended basis for measuring statistical significance of SEM components.

TABLE I: Model Fit AND ACCEPTANCE (GHolami AND KhalaJi [29],

\begin{tabular}{cc} 
SMITH AND MCMILLAN [26] AND [27]) \\
\hline Name of index & Level of acceptance \\
\hline CMIN & $2 \mathrm{df} \leq$ CMIN $\leq 3 \mathrm{df}$ \\
CMIN/df & $\leq 5$ \\
GFI & $0.9 \leq \mathrm{GFI} \leq 1.0$ \\
AGFI & $0.85 \leq \mathrm{AGFI} \leq 0.9$ \\
PNFI & $\geq 0.6$ \\
PCFI & $\geq 0.5$ \\
RMSEA & $0.05 \leq$ RMSEA $\leq 0.08$ \\
C.R & $-1.96 \geq$ C.R $\geq 1.96$ \\
\hline
\end{tabular}

\section{RESULTS AND DISCUSSION}

\section{A. Effect of Parameters on Densities}

The SEM model results on Fig. 1 and Table II shows that the particle size, pressure, mass, percentage binder and dwelling time have significantly affected on the density of the briquettes since they have p-values less than 0.05 level of significance.

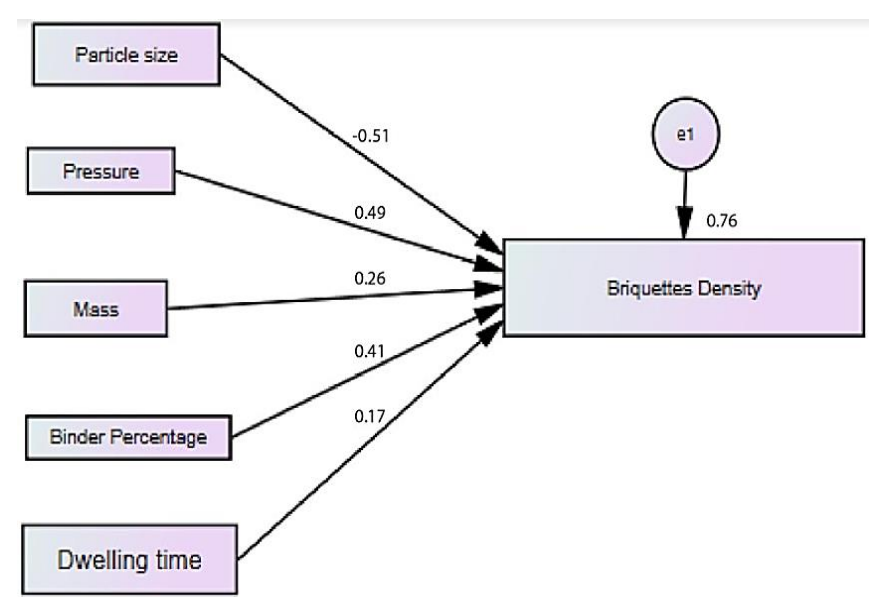

Fig. 1. Path diagram of SEM regression weights that explain factors affecting relaxed density.

The results further result shows path coefficients (standardized estimates ( $\beta$ )), $P$ - value, standard errors (S.E.) and critical ratio (C.R). The lower the value of standard error, the stronger the ability of exogenous variable to predict the endogenous variable (density). As shown, pressure, dwelling time, binder percentages and mass show the lower S.E. value of between $0.000-0.002$ which means they have the strongest 
ability to predict the density. Particle size further showed higher C.R [30] indicating that it has the strongest ability to predict the relaxed density.

\section{Particle size}

The SEM model results show that particle size has negative and significant $(\beta=-0.505, \mathrm{~S} . \mathrm{E}=0.011)$ effect on the density at $1 \%$ statistical level of significance. This demonstration that when particle size goes up by one standard deviation, density goes down by +0.505 standard deviations. Particle size shows high coefficient and critical ratio (C.R) is - 6.010 which is way out of \pm 1.96 signifying that particle size has the strongest ability to predict the briquette density. This indicates that the relaxed densities on the briquettes reduce as the grain size increase. This is for the reason that having the smallest grain means that the inter-particle and intra-particle spaces are very small and the particles pack together easily as opposed to the larger particle sizes where the spaces are larger leading to lower relaxed densities.

According to Kimutai and Kimutai [31] relaxed density of the briquette is negatively associated particle size and found that the briquette made with $0.5 \mathrm{~mm}$ particle size has the highest relaxed density as compared to the particle sizes of 1.0 $\mathrm{mm}$ and $2.0 \mathrm{~mm}$. Huko et al [7] on the other hand, attributes the increase in density to increased mechanical interlocking and adhesion between the particles, forming intermolecular bonds as the smaller the particle means higher surface area and also to the binding mechanism due to van der Waals' forces. These results are in line with [31]-[34] that large particles yield weaker bonds than small ones hence less dense.

TABLE II: REGRESSION MODEL RESULTS ON EFFECT OF PARAMETERS ON

\begin{tabular}{|c|c|c|c|c|c|c|}
\hline \multicolumn{3}{|c|}{$\begin{array}{l}\text { Relationship between } \\
\text { variables }\end{array}$} & $\begin{array}{c}\text { DENSITY } \\
\text { Standardize } \\
\text { d Estimate } \\
(\beta)\end{array}$ & S.E. & C.R. & \multirow{2}{*}{$\begin{array}{c}\begin{array}{c}\mathrm{P}- \\
\text { value }\end{array} \\
* * *\end{array}$} \\
\hline $\begin{array}{c}\text { Densit } \\
y\end{array}$ & $<---$ & $\begin{array}{l}\text { Particle } \\
\text { size }\end{array}$ & -0.505 & $\begin{array}{c}.01 \\
1\end{array}$ & -6.010 & \\
\hline $\begin{array}{c}\text { Densit } \\
y\end{array}$ & $<---$ & Pressure & 0.493 & $\begin{array}{c}.00 \\
0\end{array}$ & 5.869 & $* * *$ \\
\hline $\begin{array}{c}\text { Densit } \\
\mathrm{y}\end{array}$ & $<---$ & Mass & 0.257 & $\begin{array}{c}.00 \\
2\end{array}$ & 3.058 & $\begin{array}{c}.002 * * \\
*\end{array}$ \\
\hline $\begin{array}{l}\text { Densit } \\
\mathrm{y}\end{array}$ & $<---$ & $\begin{array}{c}\text { Binder } \\
\text { percentag } \\
\mathrm{e}\end{array}$ & 0.406 & $\begin{array}{c}.00 \\
1\end{array}$ & 4.832 & $* * *$ \\
\hline $\begin{array}{c}\text { Densit } \\
\mathrm{y}\end{array}$ & $<---$ & $\begin{array}{l}\text { Dwelling } \\
\text { time }\end{array}$ & 0.173 & $\begin{array}{c}.00 \\
0\end{array}$ & 2.059 & $.039 * *$ \\
\hline $\begin{array}{c}\text { Densit } \\
\mathrm{y}\end{array}$ & $<---$ & $\begin{array}{l}\text { Intercepts } \\
\text { (constant) }\end{array}$ & 0.351 & $\begin{array}{c}.09 \\
4\end{array}$ & 3.745 & $* * *$ \\
\hline
\end{tabular}

** Denotes values significant at $5 \%$ level of significance.

*** Denotes values significant at $1 \%$ level of significance.

\section{Compaction Pressure}

Table II also shows how pressure influences the density of the briquette. The results show that compaction pressure showed positively and significant $(\beta=493$, S.E $=0.000$, C.R $=5.869$ ) effect on the density of briquette at $1 \%$ statistical level of significance. This designate that when pressure goes up by one standard deviation, density goes up by +0.493 standard deviations. Compaction pressure shows the lowest S.E. value, 0.000 which means it has the strongest ability to predict the density of the briquette. This might be attributed to increased interlocking of neighboring particle as the compacting pressure was increased. The results are in agreement with study by researchers [21], [33], [35], [36].

\section{Mass}

The results in Table II also show how mass influences the relaxed density. Mass of residue was established to have positive and significant affect the relaxed density $(\beta=0.257$, $\mathrm{S} . \mathrm{E}=0.002, \mathrm{C} . \mathrm{R}=3.058, \mathrm{P}<0.01$ ) of fuel briquettes from cashew nutshell and cassava binder. This designate that when mass goes up by one standard deviation, density goes up by + 0.257 standard deviations. There is lack of information on literature on this parameter.

\section{Binder percentage}

Binder level of briquettes revealed a positively and significantly $(\beta=0.406$, S.E $=0.000$, C.R $=4.832, P<0.001)$ associated with the density. The results show that when binder percentage goes up by one standard deviation, density goes down by 0.406 standard deviations. Since the binder has a higher density, this can be clarified. This implies that as the amount of binder increases, the material becomes denser, and the higher the density, the denser it becomes. Similar findings were reported on the positive relationship between binder level and density [31]-[33], [37].

According to Huko et al [7], binders also have the following properties that make them suitable for use as briquetting additives: lubrication to reduce wear on production equipment, abrasion resistance of the fuel, adhesion to improve material binding, and hardness of the material textures, resulting in product longevity. In addition, Cassava binders improve the relaxed densities of cashew nutshell briquettes.

\section{Dwelling time}

Binder level of briquettes revealed a positively and significantly $(\beta=0.173, \mathrm{~S} . \mathrm{E}=0.000, \mathrm{C} . \mathrm{R}=2.059, \mathrm{P}<0.05)$ associated with the density. The results show that when dwelling time goes up by one standard deviation, density goes up by +0.173 standard deviations. This is because more stay time helps the particles to pack closer together, fill the spaces between them, and tightly adhere to one another, resulting in very compact briquettes. Also, since the particles do not have enough time to fill the inter-particle vacuum, they are only loosely packed. This is why briquettes made with no holding time have the lowest relaxed density, while those made with a 120 -second holding time have the highest relaxed density. The results are in line with other studies [8], [31].

\section{B. Sem Model Fitness}

By the using SEM method, the association between particle size, compacting pressure, binder percentage, mass, dwelling 
time and relaxed densities over the studied range was established. The experimental variables were particle size, compacting pressure binder percentage, mass and dwelling time and response was the relaxed densities. The regression is as shown:

$$
\begin{aligned}
Y=-0.505 P S+0.493 P & +0.406 \mathrm{BP}+0.257 \mathrm{M}+0.173 \mathrm{DT} \\
& +0.351
\end{aligned}
$$

where

Y - Relaxed density;

PS - Particle sizes (mm);

$\mathrm{P}$ - Compaction pressure $(\mathrm{MPa})$;

$\mathrm{BP}$ - Binder percentage $(\%)$;

M-Mass;

DT - Dwelling time;

0.351 - intercept.

The SEM model showed that particle size has the strong effects on the relaxed density of the briquettes followed by compacting pressure and thirdly binder percentage. The results are in agreement with other studies [38]-[41] and contrary to [35].

Squared multiple correlation $\left(\mathrm{R}^{2}\right)$ value of SEM for the model was computed that reveals the degree of variation in the dependent variable illustrated by independent variables. The $\mathrm{R}^{2}$ value was found to be $0.759(75.9 \%)$ which surpasses the threshold value of 0.35 as recommended by Cohen [42] and Gholami and Khalaji [29]. This indicates that the predictors of relaxed density explain 75.9 of its variances and therefore, the error variance of density is approximately $24 . \%$.

\section{CONCLUSION}

This study examined the effect of particle size, compacting pressure, binder percentage, mass and dwelling time on relaxed density fuel briquettes from cashew nutshell and cassava binder. According to the findings, particle size, compacting pressure, and percentage binder are all strong predictors of relaxed density.

\section{ACKNOWLEDGEMENT}

The authors acknowledge the support of Moi University's Centre of Excellence in Phytochemistry, Textiles, and Renewable Energy (ACE II).

\section{REFERENCES}

[1] Kimutai, S., A. Kiprop, and D. Snelder, Household Energy Utilization and Changing Behaviours: Evidence from Western Kenya. International Journal of Energy Engineering 9 (2), 36-44, 2019.

[2] Osano, A., et al., Insights into household fuel use in Kenyan communities. Sustainable Cities and Society, 2020. 55: p. 102039.

[3] Njiru, C.W. and S.C. Letema, Energy poverty and its implication on standard of living in Kirinyaga, Kenya. Journal of Energy, 2018. 2018.

[4] Tumuluru, J.S., et al., A review of biomass densification systems to develop uniform feedstock commodities for bioenergy application. Biofuels, Bioproducts and Biorefining, 2011. 5(6): p. 683-707.
[5] Bajwa, D.S., et al., A review of densified solid biomass for energy production. Renewable and Sustainable Energy Reviews, 2018. 96: p. 296-305.

[6] Kaliyan, N. and R.V. Morey, Factors affecting strength and durability of densified biomass products. Biomass and bioenergy, 2009. 33(3): p. 337-359.

[7] Huko, D.O., Investigation of mechanical and combustion characteristics of cashew nut and mango seed shells composite briquettes. 2016, Egerton University.

[8] Andayanie, W.R., et al., Biochar Briquette Makings from Cashew Nut Shell Waste and Soybean Empty Pods as Energy Alternative Sources of Stove. Research Report, 2017: p. 157-161.

[9] Oyelaran, O.A., et al., Performance evaluation of the effect of binder on groundnut shell briquette. Applied Science and Engineering Progress, 2015. 8(1): p. 11-19.

[10] Laichena, J.K., Biomass fuel in Kenya: availability and the potential for gasification. Energy exploration \& exploitation, 1991. 9(6): p. 405-421.

[11] Lubwama, M., et al., Physical and combustion properties of agricultural residue bio-char bio-composite briquettes as sustainable domestic energy sources. Renewable energy, 2020. 148: p. 1002-1016.

[12] Kituyi, E., et al., Biofuel consumption rates and patterns in Kenya. Biomass and Bioenergy, 2001. 20(2): p. 83-99.

[13] Ani, J., et al., Potentials of activated carbon produced from biomass materials for sequestration of dyes, heavy metals, and crude oil components from aqueous environment. Applied Water Science, 2020. 10(2): p. 1-11.

[14] Obi, O.F. and K.C. Okongwu, Characterization of fuel briquettes made from a blend of rice husk and palm oil mill sludge. Biomass Conversion and Biorefinery, 2016. 6(4): p. 449-456.

[15] Granado, M.P.P., et al., Effects of pressure densification on strength and properties of cassava waste briquettes. Renewable Energy, 2021. 167: p. 306-312.

[16] Ifa, L., et al., Techno-economic analysis of bio-briquette from cashew nut shell waste. Heliyon, 2020. 6(9): p. e05009.

[17] Kusekwa, M.A., Biomass conversion to energy in Tanzania: A critique. New development in renewable energy, 2013: p. 240-270.

[18] Kimutai, S.K., et al., A study on agricultural residues as a substitute to fire wood in Kenya: a Review on Major Crops. Journal of Energy Technologies and Policy, 2014. 4(9): p. 45-52.

[19] Nair, K.P., Cashew nut (Anacardium occidentale L.), in Tree Crops. 2021, Springer. p. 27-77.

[20] Sanger, S., et al., Study of carbonization for cashew nut shell. Research Journal of Chemical Sciences, 2011. 1(2): p. 43-55.

[21] Kpalo, S.Y., et al., Production and characterization of hybrid briquettes from corncobs and oil palm trunk bark under a low pressure densification technique. Sustainability, 2020. 12(6): p. 2468.

[22] Lamidi, R.O., et al., Recent advances in sustainable drying of agricultural produce: A review. Applied energy, 2019. 233: p. 367-385.

[23] Muller, D., C.M. Judd, and V.Y. Yzerbyt, When moderation is mediated and mediation is moderated. Journal of personality and social psychology, 2005. 89(6): p. 852.

[24] Preacher, K.J., D.D. Rucker, and A.F. Hayes, Addressing moderated mediation hypotheses: Theory, methods, and prescriptions. Multivariate behavioral research, 2007. 42(1): p. 185-227.

[25] Bt Wan Mohamed Radzi, C.W.J., H. Hui, and H. Salarzadeh Jenatabadi, Family Food Security and Children's Environment: A Comprehensive Analysis with Structural Equation Modeling. Sustainability, 2017. 9(7): p. 1220.

[26] Smith, T.D. and B.F. McMillan, A Primer of Model Fit Indices in Structural Equation Modeling. 2001.

[27] Schreiber, J.B., et al., Reporting structural equation modeling and confirmatory factor analysis results: A review. The Journal of educational research, 2006. 99(6): p. 323-338.

[28] Zhang, M., et al., Illness perceptions and stress: mediators between disease severity and psychological well-being and quality of life among patients with Crohn's disease. Patient preference and adherence, 2016. 10: p. 2387.

[29] Gholami, Y. and N. Khalaji, Evaluate the impact of socio-economic consumerism citizens (case study: Kashan). Research and Urban Planning, 2017. 8(29): p. 128.

[30] Hair Jr, J.F., et al., Partial least squares structural equation modeling (PLS-SEM): An emerging tool in business research. European business review, 2014. 
[31] Kimutai, K. and K.S. Kimutai, Investigation of physical and combustion properties and briquettes from cache nutshell and cassava binder. 2019.

[32] Gowthamarajan, K., et al., Preliminary study of Anacardium occidentale gum as binder in formulation of paracetamol tablets. Carbohydrate Polymers, 2011. 83(2): p. 506-511.

[33] Chungcharoen, T. and N. Srisang, Preparation and characterization of fuel briquettes made from dual agricultural waste: Cashew nut shells and areca nuts. Journal of Cleaner Production, 2020. 256: p. 120434.

[34] Oyebisi, S., T. Igba, and D. Oniyide, Performance evaluation of cashew nutshell ash as a binder in concrete production. Case Studies in Construction Materials, 2019. 11: p. e00293.

[35] Mitchual, S.J., K. Frimpong-Mensah, and N.A. Darkwa, Effect of species, particle size and compacting pressure on relaxed density and compressive strength of fuel briquettes. International Journal of Energy and Environmental Engineering, 2013. 4(1): p. 1-6.

[36] Dinesha, P., S. Kumar, and M.A. Rosen, Biomass briquettes as an alternative fuel: A comprehensive review. Energy Technology, 2019. 7(5): p. 1801011.

[37] Davies, R. and O. Davies, Physical and combustion characteristics of briquettes made from water hyacinth and phytoplankton scum as binder. Journal of combustion, 2013. 2013

[38] Lisowski, A., et al., Effects of moisture content, temperature, and die thickness on the compaction process, and the density and strength of walnut shell pellets. Renewable Energy, 2019. 141: p. 770-781.

[39] Oladeji, J. and C. Enweremadu, The effects of some processing parameters on physical and densification characteristics of corncob briquettes. International Journal of Energy Engineering, 2012. 2(1): p. 22-27.
[40] Gendek, A., et al., Evaluation of selected physical and mechanical properties of briquettes produced from cones of three coniferous tree species. Biomass and Bioenergy, 2018. 117: p. 173-179.

[41] Sunardi, S., D. Djuanda, and M.A.S. Mandra, Characteristics of charcoal briquettes from agricultural waste with compaction pressure and particle size variation as alternative fuel. International Energy Journal, 2019. 19(3): p. 139-148.

[42] Cohen, J., Statistical power analysis. 1988.

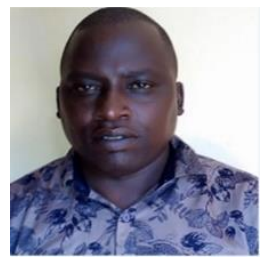

Mr. Stephen K. Kimutai was born in Uasin Gishu, Kenya on the $27^{\text {th }}$ May, 1979. He holds a Master of philosophy in Production Engineering (Manufacturing Technology Option) and is expected to graduate with $\mathrm{PhD}$ in Energy Studies in December 2021. He holds a Bachelor's degree in Mechanical and Production Engineering from Moi University.

$\mathrm{He}$ is a senior lecturer, Department of Mechanical, Production \& Energy Engineering, School of Engineering, Moi University. In addition, Kimutai is the School of Engineering Timetable Coordinator.

Mr. Kimutai is a registered Graduate Engineer with Engineers Board of Kenya. He was awarded scholarship to pursue Msc degree as a result of his First-class Honours in Bachelor's degree by Higher education loans board. He is also a research member of ASALI project. 